\title{
Screening of Chicken Genes Related to Germ Cell Development
}

Jee Young Lee*, Heebal Kim*, Duk Kyung Kim*, Ki Duk Song**, Jeong Mook Lim* and Jae Yong Han*

School of Agricultural Biotechnology, Seoul National University, Seoul 151-921, Korea* Avicore Biotechnology Institute, Hanlim Human Tower, Gyeonggi-Do 435-050, Korea **

$$
\begin{gathered}
\text { 닭에서 생식세포 발달에 관여하는 유전자 검색 } \\
\text { 이지영* · 김희발* · 김덕경* · 송기덕** · 임정묵* · 한재용* } \\
\text { 서울대학교 농업생명과학대학*, 아비코아 생명공학연구소** }
\end{gathered}
$$

$$
\text { 요 약 }
$$

본 연구에서는 Germonline 싸이트에 존재하는 유전자를 닭에 적용함에 따라 생식세포 발달과 관련 된 TCs (tentative consensus sequences)의 발현 패턴을 닭의 다양한 조직에서 관찰하였다. 따라서 생식 세포 분화와 관련된 전체 84 개(생쥐 10 개, 쥐 71 개, 사람 3 개)의 유전자 집단에 대해 BLAST 검색을 시행한 결과, 닭에 상응하는 84개의 TC중에서, 42 개의 TC가 높은 유사성을 나타냄을 확인하였다. 42 개의 TC 가운데에서 Hmgcs2와 Sycp3는 각각 정소와 생식기관 특이적으로 발현됨을 알 수 있었다. 또한, Crmp4, Cyct, Ldhc, Epha7, Pcsk4, Dnmt3a은 뇌, 정소, 난소에서만 발현되었다. 닭 유전자를 대상 으로 생식세포 발달과 관련된 유전자 탐색을 수행한 본 연구는 생식세포 분화의 메커니즘을 규명하 는데 유용한 정보의 원천으로써 제공될 수 있을 것이다.

(Key words : Chicken, Germ cell, GermOnline, Hmgcs2, Sycp3)

\section{I . INTRODUCTION}

Germ cells possess special properties due to their unique roles. Since germ cells ultimately give rise to all the tissues of a developing animal, they must remain pluripotent, also they are differentiated into highly specialized gametes. Therefore, the research to verify the mechanism of genes involved in germ cell development is highly valuable. The recent developments of large-scale DNA sequencing techniques, microarray technology and bioinformatics have been enable scientists to identify potential genes, study their patterns of expression and analyze their promoters at the genomic level (Lockhart and Winzeler, 2000). GermOnline being accessible at http://www.Germonline.org is a gateway for germ cell growth and gametogenesis (Wiederkehr et al., 2004a, 2004b). It provides a rapid access to curated information about genes as well as

Corresponding author:Dr. Jae Y. Han, Division of Animal Genetic Engineering, School of Agricultural Biotechnology, Seoul National University, Seoul 151-921, Korea Tel : +822-880-4810; Fax : +822-874-4811; E-mail : jaehan@snu.ac.kr 
microarray expression data implicated in germline development, the mitotic and meiotic cell cycle, gamete formation, and gamete function in currently 11 model species such as Homo sapiens, Mus musculus, Rattus norvegicus, Danio rerio, Drosophila melanogaster, Caenorhabditis elegans, Arabidopsis thaliana, Schizosaccharomyces pombe and Saccharomyces cerevisiae.

However, little is known of molecular requirements for specification of chicken germ cells. Thus, we suggested how many genes related to germ cell lineage in mouse, rat and human are conserved in chicken and the expression patterns of the genes in various chicken tissues.

\section{П. MATERIALS AND METHODS}

\section{Tissues}

White Leghorn chickens used in this study were kept at the University Animal Farm in Seoul National University. Six tissues including brain, spleen, liver, muscle, testis and ovary were obtained from sexually matured chickens (25 weeks old). The tissues, excluding testes and ovaries, were obtained from both male and female chickens.

\section{Extraction of mRNA and performance of RT-PCR}

According to the manufacturer's protocol, samples of chicken tissues were homogenized and total RNA was isolated using Trizol reagent (Invitrogen, Carlsbad, CA, USA). For each tissue analyzed, cDNA was synthesized from $0.5 \mu \mathrm{g}$ total RNA in $20 \mu \mathrm{l}$ reactions by reverse transcription with the Superscript III First-Strand
Synthesis System (Invitrogen).

Touchdown PCR was performed to prevent the formation of spurious bands. Each PCR reaction was performed using $0.5 \mathrm{U}$ of Taq polymerase (Biotools, Madrid, Spain) with $2 \mu \mathrm{l}$ cDNA per 20- $\mu$ l reaction volume. An initial denaturation step at $94^{\circ} \mathrm{C}$ for $2 \mathrm{~min}$ was followed by 5 rounds of touchdown cycles. The primer annealing temperature was $62^{\circ} \mathrm{C}$ in the first cycle and decreased by $0.5^{\circ} \mathrm{C}$ in every subsequent cycle. In the next 28 cycles, amplification was performed by using $94^{\circ} \mathrm{C}$ for $30 \mathrm{sec}, 60^{\circ} \mathrm{C}$ for $30 \mathrm{sec}$, and $72^{\circ} \mathrm{C}$ for $30 \mathrm{sec}$. The thermal cycling program ended with incubation at $72^{\circ} \mathrm{C}$ for $7 \mathrm{~min}$ to ensure complete extension. PCR amplification of all cDNA samples was also performed by using primers specific for the house-keeping gene, glycerol-dehyde-3-phosphate dehydrogenase (GAPDH) as a control for RNA extraction and cDNA synthesis.

\section{Search for ESTs and primer design}

To investigate possible germ cell-specific marker, we searched the pool of 84 genes related to germ cell lineage in mouse(10), rat(71) and human(3) from GermOnline site and found 84 chicken homologous TCs (tentative consensus sequences) from Gallus gallus Gene Index (GgGI) at the Institute for Genomic Research (TIGR) as performing a tBLASTn search. We selected 41 Chicken homologous TCs having Coverage of $60 \%$ and Identities and Positives of 60 70\% from the result of a BLAST search. Primer pairs for RT-PCR were designed for each of the 41 TCs using the Primer3 program (http://frodo.wi. mit.edu/cgi-bin/primer3/primer3_www.cgi). 


\section{RESULTS AND DISCUSSION}

We searched the pool of 84 genes related to germ cell lineage in mouse(10), $\operatorname{rat}(71)$ and human(3) from GermOnline site and found 84 chicken homologous TCs from GgGI. Of those, 42 chicken homologous TCs had Coverage of $60 \%$ and Identities and Positives of 60 70\% in performing a BALST search (Table 1). This suggested that many genes involved in germ cell development were conserved in chicken. We selected 41 chicken homologous TCs except for SOX9 because SOX9 has been reported frequently about expression pattern and its function in bird (Healy et al., 1996; Kent J et al., 1996)

As one of results, Hmgcs2 and Sycp3 were shown to be expressed in a testis-specific manner and a reproductive organ (testis and ovary)specific manner by RT-PCR analysis, respectively (Fig. 1). 3-hydroxy-3-methylglutaryl-Coenzyme A synthase 2 (Hmgcs2), a HMG-CoA cycle enzyme catalyzing a step in ketone-body biosynthesis (Gil-Gomez et al., 1993), is expressed in rat testis (Schlecht et al., 2003, 2004). SYCP3/ SCP3, a component of the synaptonemal complex (Lammers et al., 1994), is highly expressed in spermatocytes and round spermatids (Schlecht et al., 2004). SYCP3 appears to have an essential meiotic function in human spermatogenesis because it was found to be mutated in patients displaying azoospermia (Miyamoto et al., 2003). As a result, the expression patterns in testis of chicken Hmgcs2 and Sycp3 mean that the function of chicken Hmgcs2 and Sycp3 may be similar to mammal, on the other hand, it is interesting that Sycp3 is weakly expressed in ovary. Therefore, future research will be needed to elucidate their functions and cell-specific expression in chicken testis.
Crmp4, Epha7, Cyct, Ldhc, Pcsk4 and Dnmt3a expressed in brain, testis, and ovary (Fig. 1). Collapsin response mediator protein $4(\mathrm{Crmp} 4)$, which may regulate the plasticity of the adult nervous system (Wang and Strittmatter, 1996) and Eph receptor A7 (Epha7), which may mediate developmental effects in the nervous system (Valenzuela et al., 1995), are highly expressed in purified spermatids (Schlecht et al., 2003, 2004). Testis specific cytochrome c(Cyct), a component of the mitochondrial electron transport chain (Shima et al., 2004), is expressed in pachytene spermatocytes and round spermatids (Schlecht et al., 2003, 2004). Lactate dehydrogenase C chain (Ldhc), a member of the lactate dehydrogenase family which catalyzes the conversion of lactate to pyruvate (Sakai et al., 1987), is highly induced in spermatocytes and post-meiotic spermatids (Schlecht et al., 2003, 2004). Dnmt3a, encoding a de novo DNA methyltransferase essential for paternal and maternal imprinting (Reik and Walter, 2001; Hata et al., 2002), is required for spermatogenesis. Although Crmp4, Cyct, Ldhc, Epha7 and Dnmt3a genes are highly expressed in spermatogenesis system, it is known that these genes play important roles in nervous system, cellular function as a component of the mitochondrial electron transport chain and a catalyzer of the conversion of lactate to pyruvate and DNA methylation. Therefore, the patterns of gene expression in chicken might be related to various functions of these genes.

Proprotein convertase subtilisin/kexin type 4 (Pcsk4), which has a possible role in the developmental maturation of germ cells, is highly abundant in the rat testis (Seidah et al., 1992). However, in performing our BLAST search, Pcsk4 in rat had the highest similarity with transgolgi network protease, Furin, in chicken. It may 
Table 1. The list of the chicken tentative consensus sequences (TCs) by performing a BLAST search with GermOnline genes

\begin{tabular}{|c|c|c|c|c|c|c|}
\hline & \multirow{2}{*}{$\begin{array}{c}\text { Gene } \\
\text { symbol }\end{array}$} & \multicolumn{4}{|c|}{ The result of a BLAST search at GgGI } & \multirow[b]{2}{*}{ Biological process } \\
\hline & & Chicken TC & $\begin{array}{c}\% \\
\text { Coverage }\end{array}$ & $\begin{array}{c}\% \\
\text { Identities }\end{array}$ & $\begin{array}{c}\% \\
\text { Positives }\end{array}$ & \\
\hline 1 & Adcyap1 & TC106496 & 100 & 68 & 78 & insulin secretion \\
\hline 2 & Aqp8 & TC108639 & 67 & 55 & 70 & water transport; spermatogenesis \\
\hline 3 & Ccnb1 & TC101755 & 90 & 50 & 65 & cell cycle; regulation of cell cycle \\
\hline 4 & Chrne & NP347482 & 98 & 50 & 64 & transport; synaptic transmission; ion transport \\
\hline 5 & Crmp4 & TC102225 & 100 & 88 & 93 & neurogenesis \\
\hline 6 & Cst8 & TC121340 & 71 & 29 & 58 & \\
\hline 7 & Cyct & TC121703 & 99 & 87 & 92 & electron transport \\
\hline 8 & Fbp1 & TC123026 & 99 & 74 & 87 & gluconeogenesis; carbohydrate metabolism \\
\hline 9 & Gpd2 & TC130234 & 100 & 78 & 89 & $\begin{array}{c}\text { glycerol-3-phosphate metabolism; electron } \\
\text { transport }\end{array}$ \\
\hline 10 & Hmgcs2 & TC129011 & 61 & 72 & 85 & $\begin{array}{l}\text { ketone body biosynthesis; cholesterol } \\
\text { biosynthesis; acetyl-CoA metabolism }\end{array}$ \\
\hline 11 & Ide & TC115179 & 23 & 90 & 94 & proteolysis and peptidolysis \\
\hline 12 & Mak & TC109360 & 93 & 71 & 79 & $\begin{array}{l}\text { spermatogenesis; protein amino acid } \\
\text { phosphorylation }\end{array}$ \\
\hline 13 & Mcsp & TC118837 & 15 & 59 & 63 & sperm motility; fertilization (sensu Animalia) \\
\hline 14 & Pctp & TC135038 & 99 & 70 & 84 & lipid transport; transport \\
\hline 15 & Pim1 & TC124577 & 75 & 83 & 89 & $\begin{array}{l}\text { protein amino acid phosphorylation; cell } \\
\text { growth and/or maintenance }\end{array}$ \\
\hline 16 & Pkib & & & & & negative regulation of protein kinase activity \\
\hline 17 & Polb & TC127027 & 100 & 85 & 93 & base-excision repair; pyrimidine dimer repair \\
\hline 18 & Prm2 & BU419008 & 40 & 42 & 59 & $\begin{array}{l}\text { spermatogenesis; spermatid development; } \\
\text { nuclear organization and biogenesis; mitotic } \\
\text { chromosome condensation; chromosome }\end{array}$ \\
\hline 19 & Slc2a3 & TC124181 & 100 & 66 & 78 & transport; carbohydrate transport \\
\hline 20 & Sycp3 & TC106186 & 73 & 65 & 78 & $\begin{array}{c}\text { synaptonemal complex formation; homologous } \\
\text { chromosome segregation; male meiosis } \\
\text { chromosome segregation; male meiosis I; } \\
\text { spermatogenesis }\end{array}$ \\
\hline 21 & Tcf2 & TC131449 & 45 & 60 & 70 & regulation of transcription, DNA-dependent \\
\hline 22 & Tnp1 & & & & & sperm chromatin condensation \\
\hline 23 & Aif1 & TC122955 & 92 & 59 & $80 \%$ & macrophage activation \\
\hline 24 & Atp1a4 & TC99944 & 96 & 77 & $86 \%$ & $\begin{array}{l}\text { sperm motility; metabolism; potassium ion } \\
\text { transport; sodium ion transport }\end{array}$ \\
\hline 25 & Chn2 & TC124818 & 94 & 92 & 96 & $\begin{array}{l}\text { intracellular signaling cascade; acrosome } \\
\text { formation }\end{array}$ \\
\hline 26 & KRP2 & TC124520 & 92 & 65 & 76 & $\begin{array}{l}\text { meiotic chromosome movement; meiotic } \\
\text { spindle assembly; meiosis }\end{array}$ \\
\hline 27 & Tlbp & TC109311 & 100 & 61 & 79 & acrosome formation \\
\hline 28 & Cdc20 & TC121594 & 100 & 75 & 84 & $\begin{array}{l}\text { proteolysis and peptidolysis; regulation of cell } \\
\text { cycle; mitotic cell cycle; cell cycle }\end{array}$ \\
\hline
\end{tabular}


Table 1. The list of the chicken tentative consensus sequences (TCs) by performing a BLAST search with GermOnline genes (cont'd)

\begin{tabular}{|c|c|c|c|c|c|c|}
\hline & \multirow{2}{*}{$\begin{array}{c}\text { Gene } \\
\text { symbol }\end{array}$} & \multicolumn{4}{|c|}{ The result of a BLAST search at GgGI } & \multirow{2}{*}{ Biological process } \\
\hline & & Chicken TC & $\begin{array}{c}\% \\
\text { Coverage }\end{array}$ & $\begin{array}{c}\% \\
\text { Identities }\end{array}$ & $\begin{array}{c}\% \\
\text { Positives }\end{array}$ & \\
\hline 29 & Top2a & TC123405 & 86 & 79 & 86 & DNA topological change; DNA metabolism \\
\hline 30 & Adam1 & NP959246 & 80 & 37 & 53 & $\begin{array}{l}\text { binding of sperm to zona pellucida; fusion of } \\
\text { sperm to egg plasma membrane; fertilization } \\
\text { (sensu Animalia) }\end{array}$ \\
\hline 31 & Tpt1 & TC120477 & 84 & 99 & 100 & spermatogenesis; cell proliferation \\
\hline 32 & Prkcd & TC124695 & 98 & 80 & 88 & apoptosis \\
\hline 33 & Aqp9 & TC130395 & 91 & 61 & 77 & water transport; transport \\
\hline 34 & Ppp3r2 & TC100990 & 97 & 81 & 89 & $\begin{array}{l}\text { calcium ion sensing; calcium-mediated } \\
\text { signaling }\end{array}$ \\
\hline 35 & Adam2 & NP959246 & 94 & 31 & 47 & $\begin{array}{l}\text { fertilization (sensu Animalia); regulation of } \\
\text { cell adhesion }\end{array}$ \\
\hline 36 & Ldhc & TC121498 & 99 & 67 & 83 & glycolysis \\
\hline 37 & Sycp2 & CD761525 & 9 & 59 & 79 & sperm chromatin condensation; spermatogenesis \\
\hline 38 & Dll3 & TC130861 & 78 & 33 & 45 & \\
\hline 39 & Epha7 & TC108720 & 72 & 95 & 96 & $\begin{array}{l}\text { protein amino acid phosphorylation; } \\
\text { transmembrane receptor protein tyrosine } \\
\text { kinase signaling pathway }\end{array}$ \\
\hline 40 & Hao3 & TC132280 & 91 & 56 & 73 & electron transport \\
\hline 41 & Prim2 & TC130308 & 100 & 66 & 81 & DNA replication \\
\hline 42 & LOC171574 & TC110889 & 47 & 85 & 92 & \\
\hline 43 & Crem & TC123032 & 83 & 73 & 81 & \\
\hline 44 & Muc1 & BU432980 & & & & \\
\hline 45 & Odf2 & TC132010 & 59 & 66 & 80 & spermatid development \\
\hline 46 & Tnp2 & TC122100 & 14 & 56 & 75 & sperm chromatin condensation \\
\hline 47 & Itmap1 & TC132472 & 59 & 52 & 70 & hormone mediated signaling \\
\hline 48 & Pci & TC108772 & 90 & 38 & 57 & negative regulation of blood coagulation \\
\hline 49 & Amsh & TC110841 & 63 & 52 & 67 & cytokinin mediated signaling \\
\hline 50 & Sp10 & & & & & spermatogenesis; sperm axoneme assembly \\
\hline 51 & Sp17 & TC108005 & 92 & 31 & 48 & binding of sperm to zona pellucida \\
\hline 52 & Pcsk4 & TC127481 & 81 & 61 & 72 & \\
\hline 53 & Rcl & BU263678 & 55 & 33 & 44 & $\begin{array}{c}\text { cell growth; anti-apoptosis; regulation of } \\
\text { apoptosis }\end{array}$ \\
\hline 54 & Spam & TC129291 & 78 & 43 & 59 & binding of sperm to zona pellucida \\
\hline 55 & RABIN3 & TC126722 & 87 & 75 & 82 & \\
\hline 56 & Akap4 & TC108607 & 20 & 50 & 90 & fertilization (sensu Animalia); sperm motility \\
\hline 57 & Map17 & TC131806 & 85 & 35 & 53 & glucose transport; mannose transport \\
\hline 58 & Plcd4 & TC127627 & 62 & 37 & 53 & intracellular signaling cascade \\
\hline 59 & Krp5 & TC123073 & & & & meiosis \\
\hline 60 & Tsga10 & BU212235 & & & & \\
\hline 61 & Veli1 & CN217431 & 89 & 90 & 90 & \\
\hline 62 & Adam3 & NP959246 & 90 & 31 & 47 & regulation of cell adhesion \\
\hline 63 & Adam4 & NP959246 & 47 & 32 & 48 & regulation of cell adhesion \\
\hline
\end{tabular}


Table 1. The list of the chicken tentative consensus sequences (TCs) by performing a BLAST search with GermOnline genes (cont'd)

\begin{tabular}{|c|c|c|c|c|c|c|}
\hline & \multirow{2}{*}{$\begin{array}{l}\text { Gene } \\
\text { symbol }\end{array}$} & \multicolumn{4}{|c|}{ The result of a BLAST search at GgGI } & \multirow[b]{2}{*}{ Biological process } \\
\hline & & Chicken TC & $\begin{array}{c}\% \\
\text { Coverage }\end{array}$ & $\begin{array}{c}\% \\
\text { Identities }\end{array}$ & $\begin{array}{c}\% \\
\text { Positives }\end{array}$ & \\
\hline 64 & Adam5 & NP959246 & 75 & 33 & 50 & regulation of cell adhesion \\
\hline 65 & Adam6 & NP959246 & 87 & 29 & 47 & regulation of cell adhesion \\
\hline 66 & Tpx1 & TC119031 & 93 & 30 & 46 & $\begin{array}{c}\text { fertilization (sensu Animalia); } \\
\text { cell-cell adhesion }\end{array}$ \\
\hline 67 & ODF3 & NP346652 & & & & cytoskeleton organization and biogenesis \\
\hline 68 & Hsd3b1 & TC108855 & 100 & 52 & 67 & \\
\hline 69 & Ces3 & TC102409 & 99 & 42 & 63 & \\
\hline 70 & LOC286978 & TC100072 & 89 & 57 & 60 & \\
\hline 71 & LOC59320 & TC138688 & 10 & 25 & 46 & $\begin{array}{l}\text { G-protein signaling, adenylate cyclase } \\
\text { activating pathway }\end{array}$ \\
\hline 72 & Ube2b & TC101466 & 100 & 100 & 100 & spermatogenesis \\
\hline 73 & G6pd2 & AI981687 & 25 & 77 & 87 & glucose metabolism; spermatogenesis \\
\hline 74 & Clgn & TC121819 & 91 & 57 & 74 & $\begin{array}{l}\text { fertilization; binding of sperm to zona } \\
\text { pellucida }\end{array}$ \\
\hline 75 & Ccna1 & TC109538 & 58 & 85 & 91 & $\begin{array}{l}\text { spermatogenesis; meiosis I; regulation of cell } \\
\text { cycle }\end{array}$ \\
\hline 76 & Sycp3 & TC106186 & 74 & 63 & 79 & $\begin{array}{c}\text { meiosis; spermatogenesis; female gamete } \\
\text { generation; synaptonemal complex formation; } \\
\text { meiotic chromosome condensation }\end{array}$ \\
\hline 77 & Dnmt3l & TC101864 & 73 & 41 & 57 & $\begin{array}{l}\text { imprinting; spermatogenesis; DNA } \\
\text { methylation during gametogenesis }\end{array}$ \\
\hline 78 & Rad18 & TC124491 & 78 & 48 & 62 & $\begin{array}{l}\text { imprinting; female gamete generation; } \\
\text { spermatogenesis }\end{array}$ \\
\hline 79 & $\begin{array}{c}\text { 2310009E } \\
\text { 07Rik }\end{array}$ & TC127036 & & & & $\begin{array}{l}\text { DNA repair; response to DNA damage } \\
\text { stimulus }\end{array}$ \\
\hline 80 & Zfp145 & TC129585 & 100 & 83 & 87 & $\begin{array}{l}\text { negative regulation of transcription; cell } \\
\text { growth; cell growth and/or maintenance; } \\
\text { skeletal development; limb morphogenesis; } \\
\text { male germ-line stem cell division; germ-line } \\
\text { stem cell maintenance; spermatogenesis }\end{array}$ \\
\hline 81 & Dnmt3a & TC101864 & 84 & 86 & 88 & $\begin{array}{l}\text { imprinting; spermatogenesis; DNA } \\
\text { methylation during gametogenesis }\end{array}$ \\
\hline 82 & SOX9 & TC106036 & 94 & 83 & 86 & $\begin{array}{l}\text { primary sex determination; male sex } \\
\text { determination; sex determination, } \\
\text { establishment of } \mathrm{X} \text { : A ratio }\end{array}$ \\
\hline 83 & FOXL2 & TC136944 & 30 & 84 & 86 & $\begin{array}{l}\text { primary ovarian follicle growth; ovarian } \\
\text { follicle atresia; morphogenesis of follicular } \\
\text { epithelium }\end{array}$ \\
\hline 84 & SRY & TC108068 & 77 & 45 & 67 & male sex determination \\
\hline
\end{tabular}

The TC in the gray areas has Coverage 60\%, Identities and Positives 60 70\%. 
Appendix 1 . The list of the primer pairs used in this study.

\begin{tabular}{|c|c|c|c|c|}
\hline \# & Gene & & Primers & Product size \\
\hline 1 & Adcyap1 & $\begin{array}{c}\text { Left } \\
\text { Right }\end{array}$ & $\begin{array}{l}\text { GCTCTTAGCCCTCCTGGTCT } \\
\text { CGTTCCGTCACTCTGGAAAT }\end{array}$ & 638 \\
\hline 2 & Aqp8 & $\begin{array}{c}\text { Left } \\
\text { Right }\end{array}$ & $\begin{array}{l}\text { CATCCTGACCACCTTCCTGT } \\
\text { TTACAGTGGCTGCTGTGCTC }\end{array}$ & 563 \\
\hline 3 & Ccnb1 & $\begin{array}{c}\text { Left } \\
\text { Right }\end{array}$ & $\begin{array}{l}\text { TCCAGGTCCACTCAAGGTTC } \\
\text { GACGTTCTTGGCCATATGCT }\end{array}$ & 533 \\
\hline 4 & Chrne & $\begin{array}{c}\text { Left } \\
\text { Right }\end{array}$ & $\begin{array}{l}\text { AAGATCATCAATTCAGGGCG } \\
\text { TCATCAGTCCATCCCTCTCC }\end{array}$ & 580 \\
\hline 5 & Crmp4 & $\begin{array}{c}\text { Left } \\
\text { Right }\end{array}$ & $\begin{array}{l}\text { CCAGGAGAAAGATGGCAGAG } \\
\text { CCACAAGCATTCAACACCAC }\end{array}$ & 566 \\
\hline 6 & Cyct & $\begin{array}{c}\text { Left } \\
\text { Right }\end{array}$ & $\begin{array}{l}\text { ACGTCGTGACGTCAGTCTTG } \\
\text { ACACTTCCATTGCCATCTCC }\end{array}$ & 621 \\
\hline 7 & Fbp1 & $\begin{array}{c}\text { Left } \\
\text { Right }\end{array}$ & $\begin{array}{l}\text { CACTTCTGCTGGAGGTGTCA } \\
\text { GCTTTAAGGCATTCCTTCCC }\end{array}$ & 539 \\
\hline 8 & Gpd2 & $\begin{array}{c}\text { Left } \\
\text { Right }\end{array}$ & $\begin{array}{l}\text { TTGCTCGTTCAAGGTGACTG } \\
\text { GCTGCTCGCTGGGTTATTAG }\end{array}$ & 596 \\
\hline 9 & Hmgcs2 & $\begin{array}{c}\text { Left } \\
\text { Right }\end{array}$ & $\begin{array}{l}\text { TGTGGAGCAGTCTGAGTTGG } \\
\text { TCTGAGGACAGGTCAGGCTT }\end{array}$ & 546 \\
\hline 10 & Mak & $\begin{array}{c}\text { Left } \\
\text { Right }\end{array}$ & $\begin{array}{c}\text { AGAGTGACTGGCCAGAAGGA } \\
\text { TCCAAATTCAGCATCATCCA }\end{array}$ & 614 \\
\hline 11 & Pctp & $\begin{array}{c}\text { Left } \\
\text { Right }\end{array}$ & $\begin{array}{l}\text { TGCCTGCTTTCTTGAAGGAT } \\
\text { AGGGATTGATTCACTGACGC }\end{array}$ & 538 \\
\hline 12 & Pim1 & $\begin{array}{c}\text { Left } \\
\text { Right }\end{array}$ & $\begin{array}{l}\text { TGACTTCATCACAGAACGGG } \\
\text { AGCTGTGCAGGTGGATCTCT }\end{array}$ & 530 \\
\hline 13 & Polb & $\begin{array}{c}\text { Left } \\
\text { Right }\end{array}$ & $\begin{array}{l}\text { CCTGACACGAGTTACTGGCA } \\
\text { AACTCCAGTGACACCCAAGG }\end{array}$ & 622 \\
\hline 14 & Slc2a3 & $\begin{array}{c}\text { Left } \\
\text { Right }\end{array}$ & $\begin{array}{l}\text { TCCATGCTGTTGGTGAATGT } \\
\text { GAGCTGCAGTGTGATGGAAA }\end{array}$ & 558 \\
\hline 15 & Sycp3 & $\begin{array}{c}\text { Left } \\
\text { Right }\end{array}$ & $\begin{array}{l}\text { AATTTCGTTATGGCACCGTC } \\
\text { CTCCTGCTGTTGAGTGTCCA }\end{array}$ & 685 \\
\hline 16 & Aif1 & $\begin{array}{c}\text { Left } \\
\text { Right }\end{array}$ & $\begin{array}{l}\text { CTGCCCTTCTTGCATTTCTC } \\
\text { GTCTTTGCCTTGTAGCCAGC }\end{array}$ & 630 \\
\hline 17 & Atp1a4 & $\begin{array}{c}\text { Left } \\
\text { Right }\end{array}$ & $\begin{array}{l}\text { TGCTCGACTCAACATTCCTG } \\
\text { TTTCTTGGCTGCCTCTTCAT }\end{array}$ & 579 \\
\hline 18 & Chn2 & $\begin{array}{c}\text { Left } \\
\text { Right }\end{array}$ & $\begin{array}{l}\text { GAAAGCCCACAATACCCAGA } \\
\text { CAGAAATTGAAGTGCAGCCA }\end{array}$ & 691 \\
\hline 19 & KRP2 & $\begin{array}{c}\text { Left } \\
\text { Right }\end{array}$ & $\begin{array}{l}\text { GCAATGATTTCTCCAGGCAT } \\
\text { GTTTGCTTCTCTCAGGCACC }\end{array}$ & 604 \\
\hline 20 & Tlbp & $\begin{array}{c}\text { Left } \\
\text { Right }\end{array}$ & $\begin{array}{l}\text { AGGACCACTGCCTCACAAAG } \\
\text { GCATGAAGCTTTGGTCACTG }\end{array}$ & 501 \\
\hline 21 & Cdc20 & $\begin{array}{c}\text { Left } \\
\text { Right }\end{array}$ & $\begin{array}{l}\text { CCACCACCATGATGTCAGAG } \\
\text { GTCGTAGCGTTTCATCAGCA }\end{array}$ & 539 \\
\hline
\end{tabular}


Appendix 1. The list of the primer pairs used in this study (cont'd).

\begin{tabular}{|c|c|c|c|c|}
\hline \# & Gene & & Primers & Product size \\
\hline \multirow{2}{*}{22} & \multirow{2}{*}{ Top2a } & Left & ATGGTTACGGAGCCAAACTG & \multirow{2}{*}{563} \\
\hline & & Right & AAGAGCTCGAGGTGTTTCCA & \\
\hline \multirow{2}{*}{23} & \multirow{2}{*}{ Tpt1 } & Left & TCATCTACCGGGACCTCATC & \multirow{2}{*}{552} \\
\hline & & Right & AGCCAATTATGGTGACAGGC & \\
\hline \multirow{2}{*}{24} & \multirow{2}{*}{ Prkcd } & Left & TGGACACACCTCACTACCСA & \multirow{2}{*}{508} \\
\hline & & Right & GCACAGAAGAACACTGCCAA & \\
\hline \multirow{2}{*}{25} & \multirow{2}{*}{ Aqp9 } & Left & GGCATGTTGTGTTGGTTCTG & \multirow{2}{*}{573} \\
\hline & & Right & AAATGCTCCCAGGAATTGTG & \\
\hline \multirow{2}{*}{26} & \multirow{2}{*}{ Ppp3r2 } & Left & GCAGTTCTCCAGTCCTTTGC & \multirow{2}{*}{572} \\
\hline & & Right & AGATACAACCACTGGCTGGG & \\
\hline \multirow{2}{*}{27} & \multirow{2}{*}{ Ldhc } & Left & GGCAGCAGCTACATCAAACA & \multirow{2}{*}{678} \\
\hline & & Right & CATTCCTACGGCACCACTTT & \\
\hline \multirow{2}{*}{28} & \multirow{2}{*}{ Epha7 } & Left & GCAGGGTGAATGTGTTCCTT & \multirow{2}{*}{518} \\
\hline & & Right & TCTGTTCACTGGAAACAGCG & \\
\hline \multirow{2}{*}{29} & \multirow{2}{*}{ НаоЗ } & Left & AAGCAATGGGCACCTGTTAC & \multirow{2}{*}{693} \\
\hline & & Right & CACGCAGAATCCTCAGAACA & \\
\hline \multirow{2}{*}{30} & \multirow{2}{*}{ Prim2 } & Left & TCGCTTCCATGAACTGACTG & 517 \\
\hline & & Right & ACGGAGGTGATGGTTCTCAC & 517 \\
\hline 21 & Crom & Left & GGGCTCTGCATAGTCCTCAG & \\
\hline 31 & crem & Right & GCAACACGACTCTCCAGACA & 540 \\
\hline 32 & Dci & Left & TGAGGTTGCACAAGAAGCAC & 651 \\
\hline 32 & $\mathrm{PCl}$ & Right & GCTGGCAGAATTAGAAACGC & 651 \\
\hline & & Left & AAGAAGCAAGAACTGGCTCG & \\
\hline 33 & Amsh & Right & CAGAAACTTCAAGCATGCCA & 646 \\
\hline 24 & Dolt 1 & Left & GGCTGCTGGAGATTGAGAAC & \\
\hline 34 & PCSK4 & Right & TCСТСТСАTTGTGCACTTCG & 696 \\
\hline 25 & DAPIN2 & Left & CATCAATGTTACCGACGCAG & \\
\hline 35 & RABIN3 & Right & CGATAGGTCAGCCTCTTTGC & 556 \\
\hline 36 & Voli1 & Left & CACGCTGGACAGAGATGTTG & 506 \\
\hline 36 & Velı1 & Right & CCTTGGGAGTGTAGCGTACC & 506 \\
\hline 27 & UsdPh1 & Left & CCTGGTCACTCTGCTGAACA & \\
\hline 37 & Hsd3bI & Right & GCTATCAAGTGGCTTCTGCC & 586 \\
\hline 30 & The?h & Left & GATGCGGGACTTCAAGAGAT & 502 \\
\hline 38 & Ube2b & Right & GGTTTCCTAAACTGGAGGGC & 583 \\
\hline 39 & Clon & Left & GACAAAGGGCTTGTGTTGGT & 686 \\
\hline 39 & Cign & Right & TCСТСАТСССААТСТTСАGG & 686 \\
\hline 10 & $7 f, 145$ & Left & GCCAAAGCATTTGTCTGTGA & כ2ד \\
\hline 40 & Z1р145 & Right & CAGATGGTGCACTGGTATGG & 533 \\
\hline M & $\mathrm{D}=\mathrm{s}$ & Left & ACCAGGCCACCTACAACAAG & $\Gamma \Gamma 0$ \\
\hline 41 & Dnmt3a & Right & CAGCAGATGGTGCAGTAGGA & 559 \\
\hline
\end{tabular}


be caused by the fact that Pcsk4 in mouse contains a bacterial subtilisin-like catalytic domain closely related to that of Furin in mouse

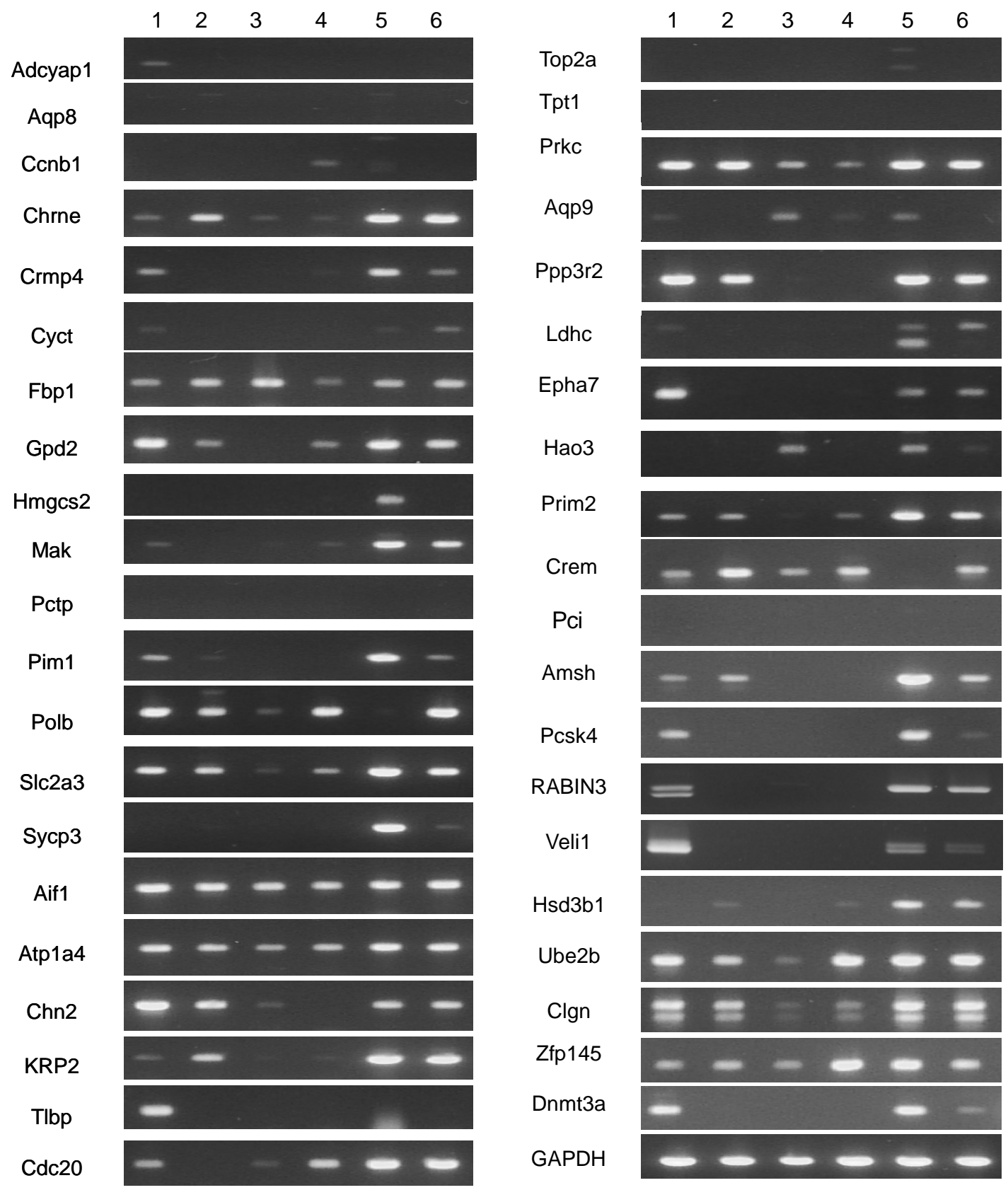

Fig. 1. The expression pattern of the chicken tentative consensus sequences (TCs) originated with GermOnline genes by RT-PCR. Lane 1: brain, lane 2: spleen, lane 3: liver, lane 4: muscle, lane 5: testis, lane 6: ovary. 
subtilisin/kexin. Also, it may be related to the fact that chicken Furin is expressed in reproductive organ as well as brain tissue.

RABIN3 and Veli1 apparently expressed as alternatively spliced transcripts in the tissues examined (Fig. 1). The PCR products amplified from the brain were of the predicted size, whereas bands of unexpected sizes were generated from the RNA extracted from testis and ovary tissues, indicating possible reproductive organ-specific alternative splicing. RABIN3, a protein that associates with the Ras-like GTPase Rab3A and Veli1 (lin-7-Ba), a gene that may mediate the formation of cell-cell junctions (Irie et al., 1999), are highly induced in spermatocytes and post-meiotic spermatids (Schlecht et al., 2003, 2004). Interestingly, in performing our BLAST search, Veli1 in rat had the highest similarity with the unknown transcripts (Gene Bank No. CN217431) in chicken. Therefore, future studies will be needed to elucidate the unknown transcripts and bands of unexpected sizes which were expressed in testis and ovary tissue.

Adcyap1 and Tlbp were also shown to be expressed in a brain-specific manner and Chrne was specific in muscle tissue (Fig. 1). The 9 numbers of candidate TCs (Ccnb1, Fbp1, Scl2a3, Aif1, Atp1a4, Prkcd, Ube2b, Clgn, Zfp145) were expressed in all tissue. There were 2 TCs (Polb, Crem) shown to be not expressed especially in testis and Chn2 shown to be not expressed especially in muscle tissue. In addition, 11 TCs (Gpd2, Mak, Pim1, KRP2, Cdc20, Aqp9, Ppp3r2, Hao3, Prim2, Amsh, Hsd3b1) were shown to be randomly expressed in various tissues.

Gene expression pattern in each tissue or organ is associated with the formation, differentiation, and development of the organ. Thus, gene expression profiling in various tissues can be used as a part of the process of screening for genes controlling the differentiation and development. In further investigation, it will be necessary to profile the spatial and temporal expression of various genes to verify the differentiation mechanisms of germ cells, the formation of genital organ and analysis of their functions.

\section{ACKNOWLEDGMENTS}

This work received grant support from the BioGreen 21 program, of the Rural Development Administration, Republic of Korea and was also supported by a graduate fellowship from the Brain Korea 21 project of the Korean Ministry of Education.

\section{ABSTRACT}

We examined the expression patterns of the chicken TCs (tentative consensus sequences) originated from GermOnline genes in various chicken tissues, applying information from GermOnline to chicken organisms. 42 TCs among 84 chicken homologous TCs from the pool of 84 genes related to germ cell lineage in mouse(10), rat(71) and human(3) had high homology based on a BLAST search. Of these, Hmgcs2 and Sycp3 was shown to be expressed in a testisspecific manner and a reproductive organ (testis and ovary)-specific manner, respectively, by RTPCR analysis. Crmp4, Cyct, Ldhc, Epha7, Pcsk4 and Dnmt3a are expressed in brain, testis, and ovary. The characterization of chicken genes originated from GermOnline in this research may give an enormously useful source of information related to germ cell development.

(Key words: Chicken, Germ cell, GermOnline, Hmgcs2, Sycp3) 


\section{REFERENCES}

1. Gil Gomez, G., Ayte, J. and Hegardt, F. G. 1993. The rat mitochondrial 3-hydroxy-3-methylglutaryl-coenzyme-A-synthase gene contains elements that mediate its multihormonal regulation and tissue specificity. Eur. J. Biochem. 213(2):773-9.

2. Hata, K., Okano, M., Lei, H. and Li, E. 2002. Dnmt3L cooperates with the Dnmt3 family of de novo DNA methyltransferases to establish maternal imprints in mice. Development. 129(8):1983-93.

3. Healy, C., Uwanogho, D. and Sharpe, P. T. 1996. Expression of the chicken Sox9 gene marks the onset of cartilage differentiation. Ann. N. Y. Acad. Sci. 785:261-2.

4. Irie, M., Hata, Y., Deguchi, M., Ide, N., Hirao, K., Yao, I., Nishioka, H. and Takai, Y. 1999. Isolation and characterization of mammalian homologues of Caenorhabditis elegans lin-7: localization at cell-cell junctions. Oncogene. 18(18):2811-7.

5. Kent, J., Wheatley, S. C., Andrews, J. E., Sinclair, A. H. and Koopman, P. 1996. A malespecific role for SOX9 in vertebrate sex determination. Development. 122(9):2813-22.

6. Lammers, J. H., Offenberg, H. H., van Aalderen, M., Vink, A. C., Dietrich, A. J. and Heyting, C. 1994. The gene encoding a major component of the lateral elements of synaptonemal complexes of the rat is related to $\mathrm{X}$-linked lymphocyteregulated genes. Mol. Cell. Biol. 14(2):1137-46.

7. Lockhart, D. J. and Winzeler, E. A. 2000. Genomics, gene expression and DNA arrays. Nature. 405:827-836.

8. Miyamoto, T., Hasuike, S., Yogev, L., Maduro, M. R., Ishikawa, M., Westphal, H. and Lamb, D. J. 2003. Azoospermia in patients heterozygous for a mutation in SYCP3. Lancet. 362(9397):1714-9.

9. Nakayama, K., Kim, W. S., Torii, S., Hosaka, M., Nakagawa, T., Ikemizu, J., Baba, T. and Murakami, K. 1992. Identification of the fourth member of the mammalian endoprotease family homologous to the yeast Kex2 protease. Its testisspecific expression. J. Biol. Chem. 267(9):5897900.

10. Reik, W. and Walter, J. 2001. Evolution of imprinting mechanisms: the battle of the sexes begins in the zygote. Nature Genetics. 27:255-256.

11. Sakai, I., Sharief, F. S. and Li, S. S. L. 1987. Molecular cloning and nucleotide sequence of the cDNA for sperm-specific lactate dehydrogenase-C from mouse. Biochem. J. 242:619-622.

12. Schlecht, U., Demougin, P., Koch, R., Hermida, L., Wiederkehr, C., Descombes, P., Pineau, C., Jegou, B. and Primig, M. 2004. Expression profiling of mammalian male meiosis and gametogenesis identifies novel candidate gene for roles in the regulation of fertility. Mol. Biol. Cell. 15(3): 1031-43.

13. Schlecht, U. and Primig, M. 2003. Mining meiosis and gametogenesis with DNA microarrays. Reproduction. 125:447-56.

14. Seidah, N. G., Day, R., Hamelin, J., Gaspar, A., Collard, M. W. and Chretien, M. 1992. Testicular expression of PC4 in the rat: molecular diversity of a novel germ cell-specific Kex2/subtilisin-like proprotein convertase. Mol. Endocrinol. 6(10): 1559-70.

15. Shima, J. E., McLean, D. J., McCarrey, J. R. and Griswold, M. D. 2004. The murine testicular transcriptome: characterizing gene expression in the testis during the progression of spermatogenesis. Biol. Reprod. 71(1):319-30.

16. Valenzuela, D. M., Rojas, E., Griffiths, J. A., Compton, D. L., Gisser, M., Ip, N. Y., Goldfarb, M. and Yancopoulos, G. D. 1995. Identification of full-length and truncated forms of Ehk-3, a novel member of the Eph receptor tyrosine kinase family. Oncogene. 10(8):1573-80.

17. Wang, L. H. and Strittmatter, S. M. 1996. A family of rat CRMP genes is differentially expressed in the nervous system. J. Neurosci. 
16(19):6197-207.

18. Wiederkehr, C., Basavaraj, R., Sarrauste, de Menthiere, C., Koch, R., Schlecht, U., Hermida, L., Masdoua, B., Ishii, R., Cassen, V., Yamamoto, M., Lane, C., Cherry, M., Lamb, N. and Primig, M. 2004a. Database model and specification of GermOnline Release 2.0, a cross-species community annotation knowledgebase on germ cell differentiation. BIOINFORMATICS. 20(5):808-811.

19. Wiederkehr, C., Basavaraj, R., Sarrauste, de Menthiere, C., Hermida, L., Koch, R., Schlecht, U., Amon, A., Brachat, S., Breitenbach, M., Briza, P., Caburet, S., Cherry, M., Davis, R.,
Deutschbauer, A., Dickinson, H. G., Dumitrescu, T., Fellous, M., Goldman, A., Grootegoed, J. A., Hawley, R., Ishii, R., Jegou, B., Kaufman, R. J., Klein, F., Lamb, N., Maro, B., Nasmyth, K., Nicolas, A., Orr-Weaver, T., Philippsen, P., Pineau, C., Rabitsch, K. P., Reinke, V., Roest, H., Saunders, W., Schroder, M., Schedl, T., Siep, M., Villeneuve, A., Wolgemuth, D. J., Yamamoto, M., Zickler, D., Esposito, R. E. and Primig, M. 2004b. GermOnline, a cross-species community knowledgebase on germ cell differentiation. Nucleic Acids Research. 32:560-7.

(접수일자 : 2007. 1. 5. / 채택일자 : 2007. 4. 11.) 